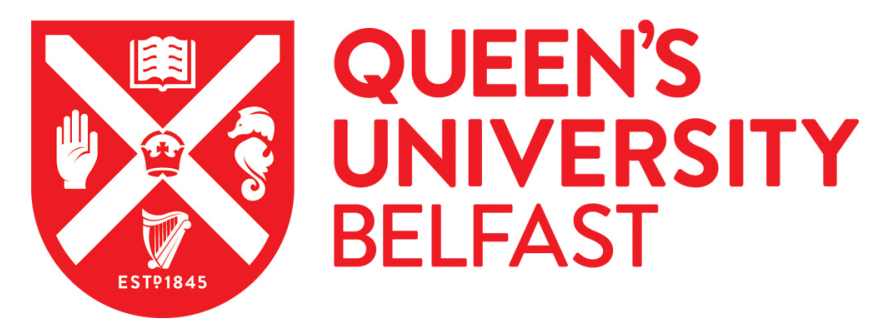

\title{
Framework for analysing continuity in students' learning experiences during primary to secondary transition in mathematics
}

Cantley, I., O'Meara, N., Prendergast, M., Harbison, L., \& O'Hara, C. (2021). Framework for analysing continuity in students' learning experiences during primary to secondary transition in mathematics. Irish Educational Studies, 4O(1), 37-49. https://doi.org/10.1080/03323315.2020.1779108

Published in:

Irish Educational Studies

Document Version:

Peer reviewed version

Queen's University Belfast - Research Portal:

Link to publication record in Queen's University Belfast Research Portal

Publisher rights

Copyright @ 2020 Informa UK Limited, trading as Taylor \& Francis.

This work is made available online in accordance with the publisher's policies. Please refer to any applicable terms of use of the publisher.

\section{General rights}

Copyright for the publications made accessible via the Queen's University Belfast Research Portal is retained by the author(s) and / or other copyright owners and it is a condition of accessing these publications that users recognise and abide by the legal requirements associated with these rights.

Take down policy

The Research Portal is Queen's institutional repository that provides access to Queen's research output. Every effort has been made to ensure that content in the Research Portal does not infringe any person's rights, or applicable UK laws. If you discover content in the Research Portal that you believe breaches copyright or violates any law, please contact openaccess@qub.ac.uk. 
Framework for analysing continuity in students' learning experiences during primary to secondary transition in mathematics

\title{
Ian Cantley ${ }^{a}$ (corresponding author), Niamh O'Meara ${ }^{b}$, Mark Prendergast ${ }^{c}$, Lorraine Harbison $^{\text {, }}$ Clare O'Hara ${ }^{\mathrm{e}}$
}

a School of Social Sciences, Education and Social Work, Queen's University Belfast, 69-71 University Street, Belfast, United Kingdom, BT7 1HL; Email: i.cantley@qub.ac.uk; Telephone: +44 (0)2890 975936; ORCID: 0000-0002-8995-6281

b EPISTEM, University of Limerick, Limerick; Email: niamh.omeara@ul.ie

c School of Education, Trinity College Dublin; Email: mark.prendergast@tcd.ie

d CASTeL, Dublin City University, Dublin; Email: lorraine.harbison@dcu.ie

e Central Statistics Office, Dublin; Email: clare.ohara@cso.ie

\begin{abstract}
The transition from primary to secondary education tends to have deleterious effects on student achievement and motivation in mathematics, and these effects have been significantly linked to lack of curricular and pedagogical continuity at transition. Curricular and pedagogical practices in each phase of schooling are influenced by a number of factors including, for example, teachers' mathematical knowledge for teaching, and a range of other school and societal level characteristics. We propose a novel theoretical framework for studying continuity of learning experiences during primary/secondary transition in mathematics which takes cognisance of these factors. The framework is based on aspects of the so-called anthropological theory of didactics, which acknowledge that mathematics learning and teaching are human activities that cannot be divorced from the broader organisational, societal and cultural contexts within which they occur; teacher attributes; and Dewey's principle of continuity of experience. Potential applications of the framework to other forms of educational transition are also signposted.
\end{abstract}

\section{Keywords}

Transition; primary; secondary; mathematics; theoretical framework

\section{Acknowledgements}

This work was supported by grants from the Irish Research Council and the Standing Conference on Teacher Education, North and South (SCoTENS). 


\section{Introduction}

High levels of mathematical competence are perceived to be crucial for the economic growth of a country, and to ensure its international competitiveness (Valero 2017). The study of mathematics equips students with logical and problem-solving skills, and mathematical proficiency is also a necessary prerequisite for many other scientific, engineering and computing disciplines. It is therefore problematic that the transition from primary to secondary education often negatively impacts upon students' performance in mathematics (Carmichael 2015; Education and Training Inspectorate and Department of Education and Skills Inspectorate 2015; Galton, Morrison, and Pell 2000; Whitley, Lupart, and Beran 2007), and their affective relationships with the discipline (Grootenboer and Marshman 2016; Martin et al. 2015). This decline in mathematical achievement and engagement has been attributed to a number of factors, including a hiatus in curricular and pedagogical continuity across the transition (Gueudet et al. 2016; Paul 2014; Witt 2011).

In this article, we propose a theoretical framework for analysing continuity issues pertaining to primary/secondary transition in mathematics, which facilitates a coherent exploration of the interplay between teacher characteristics, and school organisational and societal factors, in promoting successful transitions. The framework is based on aspects of the so-called anthropological theory of didactics (ATD) (Bosch and Gascón 2006; Chevallard 2002), which acknowledge that mathematics learning and teaching are human activities that cannot be divorced from the broader organisational, societal and cultural contexts within which they occur; teacher attributes; and Dewey's principle of continuity of experience (Dewey [1938] 1997). The novel theoretical framework we propose will be of international relevance for researchers and policymakers with an interest in improving educational transitions.

The next section outlines some of the factors that influence students' general academic achievement at transition, before focusing on mathematics-specific issues.

\section{The problematic primary to secondary transition}

\subsection{Generic issues}

The transition from primary to secondary education is acknowledged to be a potentially challenging time for young students, and there has been extensive research into the vulnerabilities that can emerge during this critical period in children's lives (Anderson et al. 2000; Evangelou et al. 2008; Galton, Hargreaves, and Pell 2003; Hopwood, Hay, and Dyment 
2016; Ryan, Shim, and Makara 2013). In negotiating the transfer from primary to secondary school, many students have to contend with organisational, developmental, social and curricular difficulties or discontinuities which have the potential to disrupt their educational trajectories (Anderson et al. 2000; Gueudet et al. 2016; Howe and Richards 2011).

At the organisational level, many students move from relatively small primary schools to much larger secondary schools; and from a school environment where they are taught most subjects by a generalist teacher to one where they are usually taught by different specialist teachers for each curriculum subject. Individually, these specialist teachers have less overall contact time with students than the primary school generalists and, consequently, less time to establish effective relationships for learning. The rigidity of the secondary school day, whereby students normally attend a number of discrete, strictly-timetabled lessons, engenders more restrictive time schedules which may, from a pragmatic perspective, place limits on the pedagogical approaches that can be utilised.

The transition from primary to secondary education occurs during early adolescence, a time of developmental change for young people which can, for some individuals, precipitate emotional difficulties that may, for example, induce mood disruptions or challenging behaviour (Topping 2011). Transition also presents tensions from a social viewpoint since peer relationships and networks can be disrupted and, given that such relationships can moderate the effects of stress, transition may negatively impact on some students' general emotional wellbeing (Jindal-Snape and Miller 2008; Topping 2011). Furthermore, transition may be accompanied by reductions in self-esteem and motivation which, in worst case scenarios, can be a precursor to mental health problems (Otis, Grouzet, and Pelletier 2005; Rice, Frederickson, and Seymour 2011). The social and emotional difficulties that can manifest themselves during early adolescence have been linked to reductions in academic motivation and achievement, thus negatively impacting on the transition to secondary education (Topping 2011). Finally, issues pertaining to curriculum continuity, in terms of both subject content and pedagogy, have been identified as significant barriers to successful primary/secondary transition by numerous researchers (Evangelou et al. 2008; Galton, Hargreaves, and Pell 2003; Sutherland et al. 2010; Topping 2011), and therefore curricular and pedagogical continuity are the principal foci of this article.

\subsection{Mathematics-specific issues}


It has been suggested that, although curriculum continuity problems are not unique to mathematics, the nature of mathematics as a discipline makes the achievement of curriculum continuity particularly challenging to accomplish (Nicholls and Gardner 1999; Witt 2011). When they embark upon secondary mathematics courses, there can be a very wide spectrum of mathematical attainment amongst students, who often come from multiple feeder primary schools (Witt 2011). The issue of curriculum discontinuity, and its potential ramifications, during the transition from primary to secondary mathematics are well documented (Attard 2010, 2013; Bicknell and Riley 2012; Gueudet et al. 2016; Paul 2014; Sdrolias and Triandafillidis 2008). Bicknell and Riley (2012) reinforced the fact that there is greater likelihood of curriculum discontinuity occurring when schools adopt a 'fresh start' approach to teaching first year secondary mathematics, whereby minimal assumptions are made about students' existing knowledge/skills at transition. Bicknell and Riley (2012) reported that such an approach can be symptomatic of secondary teachers' distrust of assessment information passed to them by feeder primary schools, a viewpoint that has been echoed by others, e.g. Vale et al. (2013).

Attard (2010, 2013) linked declines in students' levels of affective engagement with mathematics in the early stages of secondary school to the curriculum content addressed, teaching strategies employed, student workload, and approaches to assessment in secondary mathematics. Students often report significant overlaps between the curriculum content covered during the final year of primary school and the first year of secondary mathematics, coupled with reductions in the use of practical activities involving concrete resources in the performance-orientated culture of secondary education (Attard 2010; Gueudet et al. 2016). Attard's findings are further reinforced by Martin et al. (2015), who reported a significant decline in students' mathematical engagement during the transition phase. On the basis of a multilevel regression analysis relating 1,601 students' mathematics engagement to various student, home and school variables, Martin et al. (2015) indicated that school-related factors, such as school size and staff-to-student ratio, are significant predictors of engagement, and suggested greater curriculum differentiation and individual attention may help to prevent reductions in engagement levels post-transition. Students' diminished engagement with secondary mathematics after transition is problematic since affective factors have been shown to be significantly correlated with further study of mathematics and the uptake of mathematics-related careers (Frenzel, Pekrun, and Goetz 2007; Hannula et al. 2014; Wigfield et al. 2002). 
Although the direction of the relationship between mathematical affect and achievement is contested (Hannula et al. 2014; Ma and Kishor 1997), the two variables have been shown to be significantly positively correlated (Ma and Kishor 1997; Yee 2010). It is unsurprising, therefore, that transition from primary to secondary education tends to negatively impact on students' mathematical achievement (Carmichael 2015; Galton, Morrison, and Pell 2000; Vale et al. 2013; Whitley, Lupart, and Beran 2007). Based on research conducted in the UK, Galton, Morrison, and Pell (2000) found that $45 \%$ of boys and $35 \%$ of girls failed to progress in their mathematical performance during their first year of secondary education. However, it is noteworthy that Galton, Morrison, and Pell (2000) based their conclusions on students' achievement in basic numeracy tests completed pre and post-transition, which may not have been representative of the curricula being taught in the relevant school phases.

In a longitudinal study involving the performance of 3,345 students in Australia's National Assessment Program - Literacy and Numeracy (NAPLAN), which are annual tests of literacy and numeracy skills aligned with the Australian school curriculum for all students in Years 3, 5, 7 and 9, Carmichael (2015) found reductions in the growth rate of all students' mathematical attainment between 2010 (when the students were in Year 5, and typically 9 to 11 years old) and 2012 (when the students were in Year 7, and typically 11 to 13 years old). When the research was conducted, students in some Australian states transitioned to secondary education at the end of Year 6, while the transition was deferred until the end of Year 7 in others, thus meaning that some children completed Year 7 NAPLAN assessments in primary school, with the remainder taking the assessments in secondary school. The fact that students who completed the tests in a primary school also demonstrated reductions in growth rate of mathematical attainment suggests a developmental effect may contribute to the stagnation, but Carmichael (2015) reported that the reduction in growth rate was more pronounced for students who undertook their Year 7 NAPLAN tests in a secondary school environment. Carmichael (2015) concluded that transition to a secondary school tends to adversely affect students' mathematical performance, but his research indicated that students who completed the Year 7 NAPLAN tests in a primary setting showed negligible stagnation in mathematical growth when they ultimately transferred to secondary education. Carmichael (2015) thus declared that, 'for this particular cohort, the late transition to post-primary school appeared to be beneficial' (17).

Interestingly, the possibility of students' mathematical performance being adversely affected by developmental effects, occurring around the age typically associated with transition to 
secondary education, is also supported by the findings of a longitudinal study of 714 Canadian students conducted by Whitley, Lupart, and Beran (2007). Whitley, Lupart, and Beran (2007) reported significant reductions in students' mathematical attainment between grade 5 and grade 7, for both those who transitioned to grade 7 from an elementary (primary) school and students who remained in a K-8 school (a combined school catering for both primary and lower secondary education). However, the conclusions drawn by Whitley, Lupart, and Beran (2007) must be treated with caution since measures of mathematical achievement were based on parent and teacher ratings of students' achievement, and were not supplemented/supported with less subjective modes of assessment such as standardised test scores.

Internationally, the deleterious effects of the primary to secondary transition have precipitated considerable interest in initiatives and research aimed at improving curricular and pedagogical continuity in mathematics at transition (Bryan and Treanor 2007; Carraher and Schliemann 2014; Gueudet et al. 2016; Sdrolias and Triandafillidis 2008). Many initiatives have sought to strengthen relationships between primary school teachers and secondary mathematics teachers, with a view to encouraging secondary teachers to embrace more open pedagogical approaches, similar to those employed in the primary sector, to promote continuity of experience for students, and to minimise the probability of student maladaptation and disengagement (Bryan and Treanor, 2007). Numerous researchers have identified primary/secondary transition discontinuities that can arise in respect of particular mathematical domains, such as algebra or geometry, and various strategies for addressing the discontinuities have been proffered. For example, Carraher and Schliemann (2014) espoused the benefits of introducing primary school students to simple algebraic reasoning to provide a more secure foundation for later mathematical learning. Based on an analysis of continuities and discontinuities in geometry teaching within Greek primary and secondary schools, Sdrolias and Triandafillidis (2008) found that mathematics teachers in both sectors tend to rush students towards the derivation of general rules without affording them opportunities to be actively and fully involved at all stages of their construction. They concluded that teachers in both phases need to address this shortcoming in their pedagogical practices in the process of forging closer links between the two phases.

\subsection{Theoretical frameworks used to investigate curriculum continuity issues}

A number of theoretical frameworks have been used in previous studies addressing continuity issues in educational transitions. For example, Fernández and Figueiras (2014) conducted a 
study on continuity in primary/secondary mathematics transition using a framework based on what has been termed 'mathematical knowledge for teaching' (MKT), derived from the work of Ball, Thames, and Phelps (2008). MKT is the knowledge required to teach mathematics effectively, and is linked to the notion of 'pedagogical content knowledge' introduced by Shulman (1986). Paul (2014) also investigated the issue of curricular and pedagogical continuity during the transition from primary to secondary mathematics, but under the framework of Dewey's theory on continuity of experience, which posits that any educational experience influences, at least to some extent, subsequent experiences (Dewey [1938] 1997). However, the frameworks used by Fernández and Figueiras (2014) and Paul (2014) failed to take account of the potential effects on curricular/pedagogical continuity of the broader organisational, societal and cultural contexts within which the educational transitions occurred. In a study pertaining to continuity during secondary/tertiary transition in mathematics, Gueudet (2008) used ATD as her theoretical lens, which permitted the influence of broader contextual constraints to be investigated.

The current article proposes a framework for studying curriculum continuity in the context of educational transitions, which takes account of teacher attributes; continuity of experience; and the influence of organisational, societal and cultural factors. The key aspects of the theoretical framework are summarised in the following section.

\section{Proposed theoretical framework}

Didactics refers to the science of teaching discipline-specific knowledge, such as mathematical knowledge. A fundamental notion in didactics is that discipline knowledge must be adapted from its source, usually the curriculum specification in the context of school mathematics, and successively transformed into a format that is teachable and learnable. The transformation process is referred to as a didactic transposition (Chevallard 1991). Since didactic phenomena and transpositions, including those pertaining to mathematical phenomena, are concerned with the study of human practices, which are subject to various organisational, societal and cultural influences and constraints, they have a distinctly anthropological flavour.

ATD is premised on the fact that mathematics learning and teaching are purposeful human activities and, as such, ATD offers a model to describe the learning and teaching of mathematics using praxeologies (Bosch and Gascón 2006). Representing a fundamental unit 
of analysis of human actions, a praxeology consists of two components: praxis (a practical task) and logos (human reasoning). According to ATD, a human action cannot exist without some form of explanation, so that praxis and logos are inextricably linked. The praxis consists of a task and a technique, whereas the logos is constituted from a technology and a theory to justify the technology. All aspects of the didactic transpositions involved in the teaching and learning of mathematics in school contexts can be modelled by praxeologies, which fully describe the transformation of mathematical knowledge from its source to the material that is taught and learnt in classrooms. Since it is a human activity, the actual teaching and learning process can be modelled by didactic praxeologies which, in turn, lead to the establishment of mathematical praxeologies that characterise the mathematical knowledge to be acquired by students (Bosch and Gascón 2006). For example, in the context of teaching fraction equivalence, mathematical praxeologies may involve students identifying all of the fractions in a fraction wall that are equivalent to $\frac{1}{2}, \frac{1}{3}, \frac{1}{4}$, etc., and also making conjectures about the relationships between the numerators and denominators of equivalent fractions. Didactic praxeologies, on the other hand, may entail the teacher: helping students to identify equivalent fractions through effective questioning; using information technology to aid student understanding; or providing time for pairs of students to investigate equivalent fractions, etc.

The evolution, and subsequent behaviour, of the didactic and mathematical praxeologies describing students' acquisition of mathematical knowledge in a teaching scenario can be influenced, at least to some extent, by conditions and constraints that are beyond the classroom context and do not, for example, depend upon the teacher's or students' knowledge (Bosch and Gascón 2006). Chevallard (2002) proposed a hierarchy of levels of didactic codetermination to study the various influences and constraints, either within or beyond the classroom, that affect didactic transpositions. This hierarchy, which is depicted in Fig. 1, represents an important pillar of ATD (Bosch and Gascón 2014), and also provides a useful model for conceptualising factors that impact upon students' continuity of experience during the transition from primary to secondary mathematics education. 
Figure 1: Hierarchy of levels of didactic codetermination (derived from Bosch \& Gascón, 2006, p. 61)

5. Civilisation (e.g. Western culture)

4. Society (e.g. Northern Ireland)

3. School

2. Pedagogy

1. Implemented curriculum

The scale in Fig. 1 represents a hierarchy of levels which govern how mathematics is actually taught in classrooms, premised on the fact that mathematics learning and teaching cannot be divorced from the broader organisational, societal and cultural contexts within which they occur. The organisation of teaching and learning profoundly influences, and is reciprocally influenced by, constraints and conditions that exist at different levels of the hierarchy in Fig. 1.

The lowest level of the scale corresponds to the organisation of the curriculum content within the classroom (i.e. the implemented curriculum), while the instructional principles and approaches that are used in teaching the curriculum content feature at the pedagogy level of the scale. However, other conditions and constraints are imposed by the organisational context (the school, e.g. teacher knowledge, total number of students, class size, availability of learning support, students' use of technology), the society within which the school functions (e.g. the intended curriculum as dictated by a national curriculum specification), and the wider civilisation, for example, Western culture. Any change at school level, for example to introduce problem-based learning, would necessitate changes at both the pedagogical level (in terms of teacher and student roles and responsibilities) and at the implemented curriculum level of the scale (in relation to the organisation and presentation of curricular knowledge). Additionally, a more axiomatic organisation of mathematical knowledge at the implemented curriculum level would support, and be supported by, more traditional pedagogies (such as direct instruction), which would also support, and be supported by, more traditional school organisations (based on strictly-timed lessons with a single teacher and a potentially large group of students). 
Teacher characteristics, such as teaching experience and relevant professional knowledge, for example, are important variables at the school level of the hierarchy in Fig. 1, which are likely to have a direct bearing on the pedagogy and implemented curriculum that students experience in the classroom. As a constituent element of the MKT framework, Ball, Thames, and Phelps (2008) used the term horizon content knowledge (HCK) to refer to 'an awareness of how mathematical topics are related over the span of mathematics included in the curriculum' (403). Ball, Thames, and Phelps (2008) stressed that the possession of relevant HCK assists teachers to decide upon appropriate pedagogical approaches to use when teaching particular topics in the curriculum, so as to align with both prior and future learning. In both the primary and secondary phases, teachers' HCK will influence the curricular and pedagogical approaches employed in teaching mathematics, and it seems logical that the HCK of teachers at either side of the primary/secondary transition will influence the extent to which curricular and pedagogical continuity can be attained (Ball, Thames, and Phelps 2008; Fernández and Figueiras 2014).

Dewey ([1938] 1997) made repeated references to the role of continuity of experience, or what he termed the 'experiential continuum' (33), in determining whether experiences are educative or 'mis-educative' (37). He asserted that 'the principle of continuity of experience means that every experience both takes up something from those which have gone before and modifies in some way the quality of those which come after' (35). Dewey made the point that, by inculcating particular preferences or aversions, every experience either positively or negatively affects the attitudes which contribute to determining the quality of subsequent experiences. Furthermore, Dewey ([1938] 1997) contended that every experience exerts some influence on 'the objective conditions under which further experiences are had' (37). For example, when a student successfully learns elementary arithmetic, he or she considerably improves the conditions under which his or her later mathematical learning will occur since, in addition to having acquired a new skill, the student will be able to access other aspects of mathematics, such as algebra. The quality of an experience is a key determinant of how the principle of continuity of experience operates. For example, if a student has a positive experience of learning arithmetic, which induces curiosity and strengthens their desire to learn, the effect on their later mathematical learning can be transformative in the sense that they are eager to develop further mathematical skills. However, a negative learning experience has the potential to curtail the capacity for mathematical growth. 
Dewey ([1938] 1997) stressed that the principle of continuity is intimately entwined with another core tenet of his theory of educational experience, the principle of interaction, which posits that a student's experience is a product of their interaction with the environment, including both the teacher's actions and learning resources/activities. Dewey argued that any experience is determined by a combination of subjective, internal attributes of the student and objective, external characteristics of the environment. The interplay between Dewey's principles of continuity and interaction emanates from the fact that a student's reactions to the objective factors are impacted by their attitudes, habits and prior knowledge which, in turn, are shaped by the student's past experiences. Dewey ([1938] 1997) therefore concluded that the principles of continuity and interaction 'intercept and unite', and he described them as 'the longitudinal and lateral aspects of experience' (44). Accordingly, Dewey claimed that what the student 'has learned in the way of knowledge and skill in one situation becomes an instrument of understanding and dealing effectively with the situations which follow' (Dewey [1938] 1997, 44). Therefore, from a Deweyan perspective, it is the teacher's responsibility to devise student assignments that take cognisance of prior experience, and to forge links to the new experience. Such an approach is essential for the new experience to be educative rather than mis-educative. When viewed through a Deweyan lens, smooth transition from primary to secondary mathematics would appear to be predicated upon promoting continuity of students' experience, particularly in relation to curricular and pedagogical issues, whilst simultaneously minimising the potentially detrimental effects of the inevitable discontinuities.

Returning to Chevallard's levels of didactic codetermination (Chevallard 2002), the transition from primary to secondary mathematics can be modelled by the diagram in Fig. 2. The primary school is represented by the scale on the left-hand side of the diagram, while the scale on the right-hand side represents the secondary school. Curriculum continuity at transition is represented by continuity between level one of each scale, while pedagogical continuity is associated with continuity at level two of the scales. By ensuring curricular and pedagogical continuity in the primary/secondary transition, this should help to maximise the probability of continuity in the didactic transpositions involved in the learning and teaching of mathematics across the transition, thus promoting continuity in students' learning experiences. However, as noted above, there are inherent differences between primary and secondary schools with respect to their organisational structures and how mathematics teaching and learning are regulated within classrooms (at level three of each scale), and these 
have the potential to impact upon the pedagogy and implemented curriculum (Gueudet et al. 2016), possibly leading to discontinuities in students' learning experiences at transition. If the primary to secondary transition occurs within a single country, it might reasonably be assumed that factors at levels four and five of each scale should not impact on the pedagogy and implemented curriculum at levels one and two. However, it is important to note there are potential asymmetries or discontinuities originating at the societal level due, for example, to the high-stakes examinations, used to determine future educational and career pathways, that are taken by students towards the end of their secondary school careers in most countries, and possible discontinuities between the intended curricula for primary and secondary mathematics (Witt 2011), which could influence students' experiences in secondary education.

Fig. 2: Model for primary to secondary transition

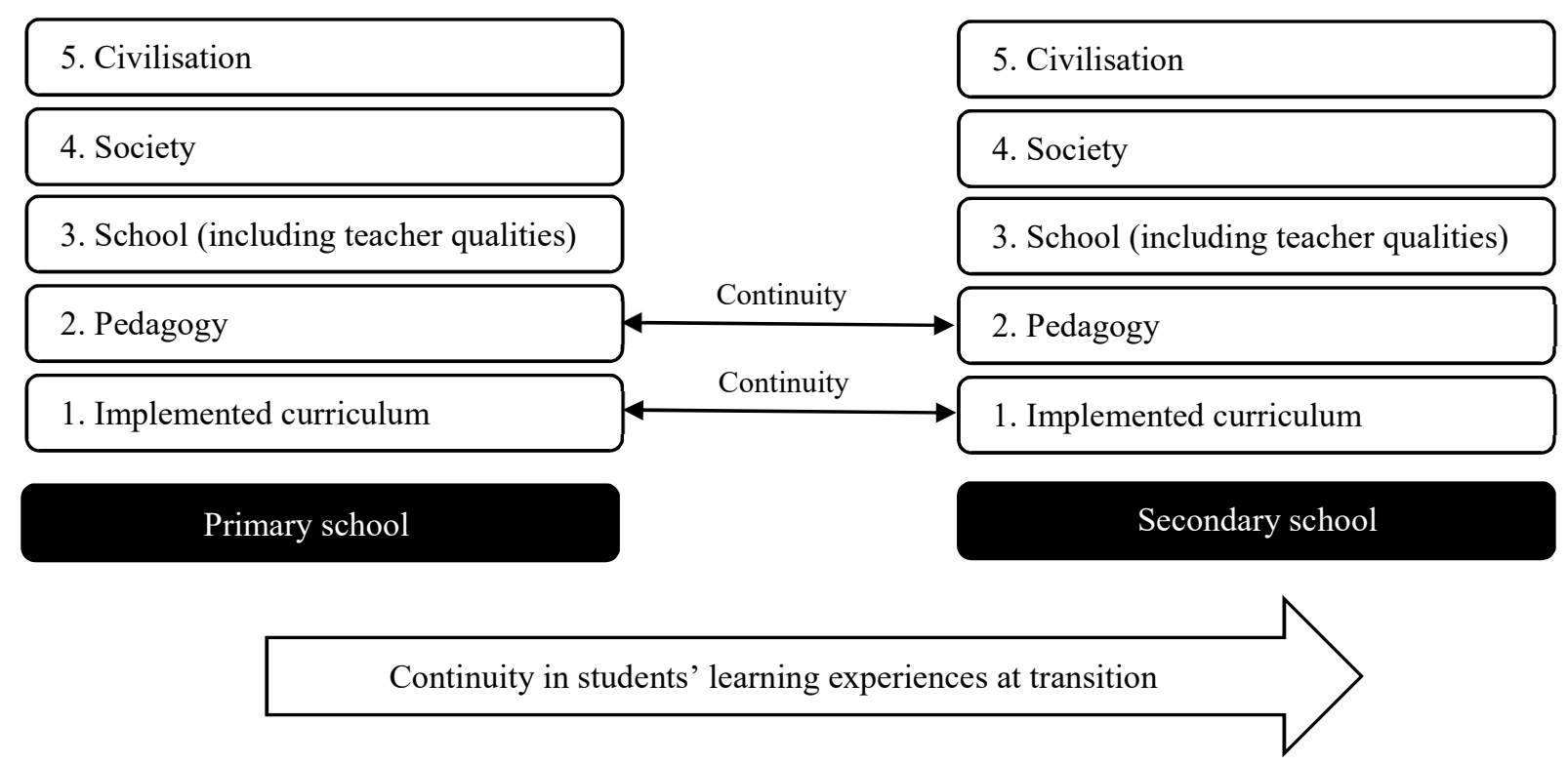

\section{Conclusion}

Transition from primary to secondary mathematics has been linked to declines in students' attitudes to mathematics and their mathematical achievement (Attard 2013; Carmichael 2015; Grootenboer and Marshman 2016; Martin et al. 2015; Whitley, Lupart, and Beran 2007). In the current article, a novel theoretical framework has been proposed for studying continuity of students' learning experiences, which is considered to be an important factor in promoting positive attitudes and achievement, during primary/secondary transition in mathematics. This framework permits the investigation of the effects of a range of school and societal level variables on students' mathematical learning experiences. 
Although the theoretical framework pertains to the transition from primary to secondary mathematics, the framework will be of relevance to educational researchers more generally. Based on a synthesis of relevant teacher attributes, Chevallard's levels of didactic codetermination (Bosch and Gascón 2006; Chevallard 2002), and Dewey’s principle of continuity of experience (Dewey [1938] 1997), the framework could be adapted for use in studies pertaining to curricular and pedagogical continuity in other educational transitions. For example, the influence of generic teacher characteristics, such as cross-phase pedagogical content knowledge, rather than mathematical HCK, on curricular/pedagogical practices and continuity at levels one and two of the framework could be investigated. The bioecological theory of human development (Bronfenbrenner and Morris 1998) permits examination of the effects of a range of factors, from direct environmental to wider societal variables, on student and teacher behaviours, and the theory has been used to analyse curriculum continuity issues in educational transitions (O'Toole, Hayes, and Mhic Mhathúna 2014). However, we contend that our theoretical framework more explicitly incorporates factors of direct relevance to curricular and pedagogical continuity in educational transitions. Accordingly, the framework will be of international relevance for researchers and policymakers who are interested in improving transitions, and it provides a readymade lens for studies aimed at enhancing curricular and pedagogical continuity, which are posited to increase the probability of successful educational transitions. 


\section{References}

Anderson, L. W., Jacobs, J., Schramm, S., and Splittgerber, F. 2000. "School transitions: beginning of the end or a new beginning?" International Journal of Educational Research 33: 325-339.

Attard, C. 2010. 'Students' experiences of mathematics during the transition from primary to secondary school." In Shaping the future of mathematics education: Proceedings of the 33rd annual conference of the Mathematics Education Research Group of Australasia, edited by L. Sparrow, B. Kissane, and C. Hurst, 53-60. Fremantle: MERGA.

Attard, C. 2013. “'If I had to pick any subject, it wouldn't be maths': Foundations for engagement with mathematics during the middle years." Mathematics Education Research Journal 25 (4): 569-587.

Ball, D. L., Thames, M. H., and Phelps, G. 2008. "Content knowledge for teaching: What makes it special?" Journal of Teacher Education 59 (5): 389-407.

Bicknell, B., and Riley, T. 2012. "Investigating transitions in mathematics from multiple perspectives." Mathematics Education Research Journal 24 (1): 1-17.

Bosch, M., and Gascón, J. 2006. "Twenty-five years of the didactic transposition." ICMI Bulletin 58: 51-65.

Bosch, M., and Gascón, J. 2014. "Introduction to the anthropological theory of the didactic (ATD)." In Networking of theories as a research practice in mathematics education, edited by A. Bikner-Ahsbahs, and S. Prediger, 67-83. Dordrecht: Springer.

Bronfenbrenner, U., and Morris, P. A. 1998. "The ecology of developmental processes." In Handbook of child psychology, vol. 1: Theoretical models of human development $\left(5^{\text {th }}\right.$ edition), edited by W. Damon, and R. M. Lerner, 993-1023. New York, NY: Wiley.

Bryan, R., and Treanor, M. 2007. Evaluation of pilots to improve primary to secondary school transitions. Glasgow: Scottish Executive Social Research.

Carmichael, C. 2015. "Transitioning to secondary school: The case of mathematics." Australian Journal of Educational \& Developmental Psychology 15: 13-23. 
Carraher, D., and Schliemann, A. D. 2014. "Early algebra teaching and learning.” In Encyclopedia of Mathematics Education, edited by S. Lerman, 193-196. Dordrecht: Springer.

Chevallard, Y. 1991. La transposition didactique: Du savoir savant au savoir enseigné [Didactic transposition: From scholarly knowledge to taught knowledge]. Grenoble: La Pensée Sauvage, Editions.

Chevallard, Y. 2002. “Organiser l'étude 3. Écologie \& regulation [To organize study 3. Ecology \& regulation]." In Actes de la 11e école de didactique des mathématiques, edited by J. L. Dorier, M. Artaud, M. Artigue, R. Berthelot, and R. Floris, 41-56. Grenoble: La Pensée Sauvage.

Dewey, J. [1938] 1997. Experience and education. New York, NY: Touchstone.

Education and Training Inspectorate, and Department of Education and Skills Inspectorate. 2015. A joint report by the Education and Training Inspectorate and the Department of Education and Skills Inspectorate on promoting and improving numeracy in postprimary schools. Belfast \& Dublin: Authors. Retrieved from https://www.education.ie/en/Publications/Education-Reports/Best-PracticeGuidelines-in-Numeracy-Provision-at-Post-Primary-Level.pdf

Evangelou, M., Taggart, B., Sylva, K., Melhuish, E., Sammons, P., and Siraj-Blatchford, I. 2008. What makes a successful transition from primary to secondary school? London: Department for Children Schools and Families.

Fernández, S., and Figueiras, L. 2014. "Horizon content knowledge: Shaping MKT for a continuous mathematical education." REDIMAT 3 (1): 7-29.

Frenzel, A. C., Pekrun, R., and Goetz, T. 2007. "Girls and mathematics - A 'hopeless' issue? A control-value approach to gender differences in emotions towards mathematics." European Journal of Psychology of Education 22 (4): 497-514.

Galton, M., Morrison, I., and Pell, T. 2000. "Transfer and transition in English schools: Reviewing the evidence." International Journal of Educational Research 33: 341363.

Galton, M., Hargreaves, L., and Pell, T. 2003. "Progress in the middle years of schooling: Continuities and discontinuities at transfer." Education 3-13 31 (2): 9-18. 
Grootenboer, P., and Marshman, M. 2016. Mathematics, affect and learning: Middle school students' beliefs and attitudes about mathematics education. Singapore: Springer.

Gueudet, G. 2008. "Investigating the secondary-tertiary transition.” Educational Studies in Mathematics 67 (3): 237-254.

Gueudet, G., Bosch, M., diSessa, A. A., Kwon, O. N., and Verschaffel, L. 2016. Transitions in mathematics education (ICME-13 topical surveys). Basel: Springer.

Hannula, M. S., Bofah, E., Tuohilampi, L., and Mestämuuronen, J. 2014. “A longitudinal analysis of the relationship between mathematics-related affect and achievement in Finland." In Proceedings of the 38th conference of the international group for the psychology of mathematics education and the 36th conference of the North American chapter of the Psychology of Mathematics Education (vol. 3), edited by S. Oesterle, P. Liljedahl, C. Nicol, and D. Allan, 249-256. Vancouver: PME.

Hopwood, B., Hay, I., and Dyment, J. 2016. "The transition from primary to secondary school: Teachers' perspectives." The Australian Educational Researcher 43 (3): 289307.

Howe, A., and Richards, V., eds. 2011. Bridging the transition from primary to secondary school. Abingdon: Routledge.

Jindal-Snape, D., and Miller, D. 2008. "A challenge of living? Understanding the psychosocial processes of the child during primary-secondary transition through resilience and self-esteem theories." Educational Psychology Review 20 (3): 217-236.

Ma, X., and Kishor, N. 1997. “Assessing the relationship between attitude toward mathematics and achievement in mathematics: A meta-analysis." Journal for Research in Mathematics Education 28 (1): 26-47.

Martin, A. J., Way, J., Bobis, J., and Anderson, J. 2015. "Exploring the ups and downs of mathematics engagement in the middle years of school." Journal of Early Adolescence 35 (2): 199-244.

Nicholls, G., and Gardner, J. 1999. Pupils in transition. Abingdon: Routledge.

Otis, N., Grouzet, F., and Pelletier, L. G. 2005. "Latent motivational change in an academic setting: A 3-year longitudinal study.” Journal of Educational Psychology 97 (2): 170 183. 
O’Toole, L., Hayes, N., and Mhic Mhathúna, M. 2014. "A bio-ecological perspective on educational transition." Procedia - Social and Behavioral Sciences 140: 121-127.

Paul, M. 2014. "Managing the transition from primary school mathematics to secondary school mathematics: Teachers' and learners' perspectives." Mediterranean Journal of Social Sciences 5 (25): 205-215.

Rice, F., Frederickson, N., and Seymour, J. 2011. “Assessing pupil concerns about transition to secondary school." British Journal of Educational Psychology 81 (2): 244-263.

Ryan, A. M., Shim, S. S., and Makara, K. A. 2013. "Changes in academic adjustment and relational self-worth across the transition to middle school." Journal of Youth and Adolescence 42 (9): 1372-1384.

Sdrolias, K. A., and Triandafillidis, T. A. 2008. "The transition to secondary school geometry: can there be a 'chain of school mathematics'?" Educational Studies in Mathematics 67 (2): 159-169.

Shulman, L. S. 1986. "Those who understand: Knowledge growth in teaching." Educational Researcher 15 (2): 4-14.

Sutherland, R., Ching Yee, W., McNess, E., and Harris, R. 2010. Supporting learning in the transition from primary to secondary schools. Bristol: University of Bristol. Retrieved from http://www.bristol.ac.uk/medialibrary/sites/education/migrated/documents/transition-bristoluniversity.pdf

Topping, K. 2011. 'Primary-secondary transition: Differences between teachers' and childrens' perceptions.” Improving Schools 14 (3): 268-285.

Vale, C., Weaven, M., Davies, A., Hooley, N., Davidson, K., and Loton, D. 2013. “Growth in literacy and numeracy achievement: evidence and explanations of a summer slowdown in low socio-economic schools." The Australian Educational Researcher 40 (1): 1-25.

Valero, P. 2017. "Mathematics for all, economic growth, and the making of the citizenworker." In Political sociology and transnational educational studies: The styles of reason governing teaching, curriculum and teacher education, edited by T. S. Popkewitz, J. Diaz, and C. Kirchgasler, 117-132. New York, NY: Routledge. 
Whitley, J., Lupart, J. L., and Beran, T. 2007. "Differences in achievement between adolescents who remain in a K-8 school and those who transition to a junior high school." Canadian Journal of Education 30 (3): 649-669.

Wigfield, A., Battle, A., Keller, L. B., and Eccles, J. S. 2002. "Sex differences in motivation, self-concept, career aspiration, and career choice: Implications for cognitive development." In Biology, society, and behavior: The development of sex differences in cognition, edited by A. McGillicuddy-De Lisi, and R. De Lisi, 93-124. Westport, CT: Ablex.

Witt, M. 2011. "Mathematics and transition." In Bridging the transition from primary to secondary school, edited by A. Howe and V. Richards, 88-98. Abingdon: Routledge.

Yee, L. S. 2010. "Mathematics attitudes and achievement of junior college students in Singapore." In Shaping the future of mathematics education: Proceedings of the 33rd annual conference of the Mathematics Education Research Group of Australasia, edited by L. Sparrow, B. Kissane, and C. Hurst, 681-688. Fremantle: MERGA. 